\title{
Phobia of COVID-19 on people who aged 18 and older
}



\section{SUMMARY}

OBJECTIVES: Our aim was to evaluate the participants with the COVID-19 scale in order to see the effects of the COVID-19 pandemic on people, which has affected the whole world along with our country, to be able to take the necessary precautions for the current pandemic and similar pandemics and to minimize the negative aspects globally.

METHODS: A total of 1010 people who aged 18 and older (between the ages of 18-76) were included in the research. Besides from the personal information of people who aged 18 and older such as a city of residence, age, gender, profession, education, the number of people who live in the same house, their chronic illnesses, marital status, and the existence of a child, a 20-question phobia of COVID19 scale was carried out. The results were $95 \%$ reliable, and their significance was evaluated to be on $p<0.05$ level.

RESULT: The COVID-19 Phobia Scale point for women was $54.97 \pm 14.44$ while it was $51.28 \pm 14.06$ for men, and between the two groups, there is a high level of significant difference $(p<0.05)$ statistically, COVID-19 Phobia Scale point of people who have chronic illnesses is $56.51 \pm 15.84$, meanwhile, the point of people who have no chronic illnesses was found to be $52.96 \pm 13.99$, and it was detected that this difference was statistically significant $(p<0.05)$.

CONCLUSION: Besides the COVID-19 pandemic affecting the whole society, we see that the women population and people who have chronic illnesses are going through much more fear and anxiety.

KEYWORDS: COVID-19. Pandemic. Phobia.

\section{INTRODUCTION}

In December 2019, a pneumonia that started in Wuhan, the capital of the Hubei Province in China, which has no known factor and does not respond to the treatments, was observed. After studies were carried out, it has been understood that the illness that is named as coronavirus disease 2019 (COVID-19) (severe acute respiratory syndrome coronavirus 2 (SARS-CoV-2)) was caused by a new coronavirus, and it was transformed into an epidemic disease and took over the whole world in a terrifying manner. It is still causing a lot of people to experience psychological, organic disruptions and death ${ }^{1,2}$.
As per the WHO's instructions, national administrations are taking various precautions against this new epidemic that threatens the global health of people spreading from China, to protect the health of citizens and to come out of the epidemic with the least damage ${ }^{3}$. However, despite taking strict precautions, the affected area of the epidemic and the death cases connected to it have been monitored to be increasing continuously, which causes serious concerns on an international level ${ }^{4}$.

This study is considered to be a source of light on the literature to see the effects of the mentioned pandemic on people in our country, to be able to take the necessary precautions

\footnotetext{
${ }^{1}$ Bezmialem Vakif University, Faculty of Medicine Hospital, Department of Internal Medicine - Istanbul, Turkey.

${ }^{2}$ Istanbul Provincial Health Directorate, Department of Hospital Services - Istanbul, Turkey.

*Corresponding author: muharremkiskac@gmail.com

Conflicts of interest: the authors declare there are no conflicts of interest. Funding: none.

Received on July 11, 2021. Accepted on August 14, 2021.
} 
against the current pandemic and similar pandemics, and to minimize the negative aspects globally.

\section{Aim}

This study was conducted to determine COVID-19 (SARSCoV-2) phobia and personal characteristics related to it on people who aged 18 and older.

\section{Hypotheses}

a) COVID-19 phobia is high in people who aged 18 and older.

b) Factors such as a city of residence, age, gender, profession, education, the number of people who live in the same house, their chronic illnesses, marital status, the existence of a child have an effect on the COVID-19 phobia of people who aged 18 and older.

\section{Variables}

Independent variables included city of residence, age, gender, profession, education, the number of people who live in the same house, the number of chronic illnesses they have, marital status, and the existence of a child.

Dependent variables included average point of the COVID-19 Phobia Scale (C19P-S).

\section{METHODS}

To determine the phobia of COVID-19 on people who aged 18 and older, a descriptive study was planned; after getting written permissions from writers of scales, an approval was taken from the Health Ministry and ethics committee; and after that in July 2020, the patient information were collected. The research was carried out online and 1010 people (between the ages of 18-76) who aged 18 and older were included in it. No exclusion criteria were determined.

Participants who accepted to join the research voluntarily were informed about their rights and the research properly and their "informed consent" was obtained prior to the research. All rights of the participants were respected and attention was paid to the principles of voluntarism and confidentiality.

\section{Data collection tools}

- Personal information form: It is a form consisting of clauses about the city of residence, age, gender, profession, education, the number of people who live in the same house, their chronic illnesses, marital status, and the existence of a child of a person who aged 18 and older.

- COVID-19 phobia scale: The sample of Arpaci et al.'s research consists of 1250 people who aged 18 and older. The C19P-S is a 5-point Likert-type self-evaluation scale which was developed to evaluate the phobia that could develop against coronavirus. Scale items are evaluated between 1 "I certainly do not agree" and 5 "I certainly agree." Items 1, 5, 9, 13, 17 and 20 evaluate the Psychological subdimension; 2, 6, 10, 14, and 18 evaluate the Somatic subdimension; 3, 7, 11, 15, and 19 evaluate the Social subdimension; and 4, 8, 12, and 16 evaluate the Economic subdimension. Subdimension scores are obtained by the total score of the answers given to the items in that subdimension, meanwhile the total C19P-S score is obtained by the sum of the subdimension scores and ranges from 20-100 points. The height of the scores indicates the height in the subdimensions and general corona phobia ${ }^{5}$.

While the data obtained in the research are evaluated, IBM SPSS statistics 22.0 program was used for statistical analyses. While evaluating the study data, besides descriptive statistical methods (i.e., mean, standard deviation, and frequency), the Student's $t$ test was used for comparing normally distributed data, and the Mann-Whitney $U$ test was used for comparing non-normally distributed data. To evaluate the correlation between data, Pearson's correlation analysis was used for normally distributed data and Spearman's correlation analysis was used for data that did not show normal distribution. The results were $95 \%$ reliable, and its significance was evaluated to be on a $\mathrm{p}<0.05$ level.

\section{RESULTS}

A total of 1010 people, 640 females (63.4\%) and 370 males $(36.6 \%)$, were included in the study. The total average age of the participants was 36.54 years and $37.95 \pm 11.12$ years for men and $35.73 \pm 9.16$ years for women, and there is a statistically significant difference between women and men in terms of age $(\mathrm{p}<0.05)$.

The C19P-S score was $54.97 \pm 14.44$ in females and $51.28 \pm 14.06$ in males, and there was a statistically high significant difference between the two groups $(\mathrm{p}<0.05)$ (Table 1$)$.

While the C19P-S score of the participants with chronic disease $(n=185)$ was $56.51 \pm 15.84$, it was $52.96 \pm 13.99$ for those without the chronic disease $(n=825)$. There was a statistically significant difference between the two groups $(\mathrm{p}<0.05)$ (Table 1).

The married participants $(\mathrm{n}=672)$ had a C19P-S score of $54.28 \pm 14.50$ while the unmarried $(\mathrm{n}=338)$ C19P-S score was $52.29 \pm 14.14$, and there was a statistically significant difference between the two groups $(\mathrm{p}<0.05)$ (Table 1$)$. 
Table 1. Relationship of COVID-19 phobia scale score between groups.

\begin{tabular}{|c|c|c|}
\hline & $\begin{array}{l}\text { COVID-19 } \\
\text { phobia scale } \\
\text { score }\end{array}$ & p-value \\
\hline Women $(n=640)$ & $54.97 \pm 14.44$ & \multirow{2}{*}{0.001} \\
\hline Men $(n=370)$ & $51.28 \pm 14.06$ & \\
\hline $\begin{array}{l}\text { People with chronic diseases } \\
(n=185)\end{array}$ & $56.51 \pm 15.84$ & \multirow{2}{*}{0.002} \\
\hline $\begin{array}{l}\text { People with no chronic } \\
\text { diseases }(n=825)\end{array}$ & $52.96 \pm 13.99$ & \\
\hline Married $(n=672)$ & $54.28 \pm 14.50$ & \multirow{2}{*}{0.003} \\
\hline Unmarried $(n=338)$ & $52.29 \pm 14.14$ & \\
\hline People with a child $(n=620)$ & $54.27 \pm 14.73$ & \multirow{2}{*}{0.061} \\
\hline People with no child $(n=390)$ & $52.52 \pm 13.9$ & \\
\hline 40 and older $(n=375)$ & $54.07 \pm 13.94$ & \multirow{2}{*}{0.164} \\
\hline Under 40 years old $(n=635)$ & $53.34 \pm 14.68$ & \\
\hline
\end{tabular}

While the C19P-S score of the participants $(\mathrm{n}=620)$ with children was $54.27 \pm 14.73$, it was $52.52 \pm 13.9$ for those without children $(n=390)$. There was no statistically significant difference between the two groups ( $p>0.05$ ) (Table 1).

Taking the age of 40 as the limit, the C19P-S score of the participants aged 40 years and above was $54.07 \pm 13.94(\mathrm{n}=375)$, while the C19P-S score under 40 years old was $53.34 \pm 14.68$ $(\mathrm{n}=635)$ and the difference between the two groups was not statistically significant $(\mathrm{p}>0.05)$ (Table 1$)$.

When we look at the correlation between age and C19P-S score, no significant correlation was found $(r=0.015 ; p>0.05)$. There was no significant correlation between the number of people living with them at home and the C19P-S score $(\mathrm{r}=0.025 ; \mathrm{p}>0.05)$.

Among the 20 questions asked in the scale, the answer to the question "I am extremely afraid of the possibility of someone in my family getting coronavirus" was the highest with 3.71, while the answer to the question "fear of getting coronavirus worries me a lot" was the second with a score of 3.44, and the answer to the question "uncertainties about coronavirus worries me seriously" was the third with a score of 3.36 (Table 2).

\section{DISCUSSION}

In the performed literature review, no studies were found on COVID-19 phobia except a few studies carried out with different scales. In addition, there are various studies on COVID-19-induced anxiety, sleep disorders, and depression. In the study, it was determined that the C19P-S evaluation results were statistically significantly higher for women compared to men. It is also seen in the study of Xi Liu et al. ${ }^{1}$ (which examined the psychological situation and behavioral changes in the society of COVID-19 in China where the epidemic emerged) that women are more affected. Again, Özdin et al. found in their study investigating the rates of depression and anxiety in Turkish society during COVID-19 that women were at higher risk and female gender was an independent risk factor in this respect ${ }^{6}$. Again, in the study conducted by Qui J et al. in China, where the psychological situation in COVID-19 was evaluated with a large scale of participants, it was found that women were much more vulnerable to stress and were more likely to develop post-traumatic stress disorder ${ }^{7}$. As it can be understood from this and similar studies, it is seen that women experience stress, phobia, and anxiety more intensely and are more sensitive than men in the face of traumatic events due to them being more emotional.

In the study, the C19P-S scores of the participants with various chronic diseases were found to be significantly higher than the participants without a chronic disease. In a study that evaluates stress, anxiety, and depression conducted by Ozamiz et al. in Spain where the epidemic was severe, it was observed that people with chronic diseases had higher levels of stress, anxiety, and depression compared to participants who did not report such diseases ${ }^{8}$. For sure, this is an expected situation. Since the beginning of the epidemic, because both WHO and other health authorities have stated that the COVID-19 will be more severe and mortal in individuals with chronic diseases, it is understood that individuals with chronic diseases experience more fear, anxiety, and depression because they see themselves in a more risky group.

Again, in the study, it was determined that the C19P-S scores of the married participants were statistically significant compared to the unmarried participants; although the C19P-S scores of the participants with children were higher than those without children, this difference was not found significant. Again, no significant difference was found between those living alone at home and those living with more than one person in terms of scores on the C19P-S. At the same time, no significant correlation was found in the correlation assessment between the number of people the participant lives with at home and the score of the C19P-S. In the COVID-19-based panic and generalized anxiety assessment made by Islam et al. on Bangladesh society, the level of panic and anxiety was found to be significantly higher in those who were married and those living in a large family at a shared home 9 . In our study, this is similar to the higher C19P-S scores in married patients, and this may be due to an additional fear in the participant's family; however, out of 20 questions in C19P-S, "I am extremely afraid of 
Table 2. COVID-19 phobia scale.

\begin{tabular}{|c|c|c|}
\hline Subdimensions & Questions & Scores \\
\hline \multirow{6}{*}{$\begin{array}{l}\text { Psychological } \\
\text { Subdimension }\end{array}$} & The fear of catching the coronavirus worries me a lot. & 3.44 \\
\hline & I'm extremely afraid of the possibility of someone from my family catching the coronavirus. & 3.71 \\
\hline & News of deaths caused by coronavirus worries me extremely. & 3.21 \\
\hline & The uncertainties about the coronavirus worry me seriously. & 3.36 \\
\hline & The speed of coronavirus spreading makes me panic extremely. & 3.11 \\
\hline & $\begin{array}{l}\text { I Argue (or want to) furiously with those around me because of the insensitive behavior of } \\
\text { people toward the coronavirus. }\end{array}$ & 3.12 \\
\hline \multirow{5}{*}{$\begin{array}{l}\text { Somatic } \\
\text { Subdimension }\end{array}$} & I have stomach cramps because of coronavirus. & 2.01 \\
\hline & I have chest pain because of coronavirus. & 2 \\
\hline & My hands and feet tremble because of coronavirus. & 1.91 \\
\hline & I experience sleeping problems because of the fear of coronavirus. & 1.91 \\
\hline & Coronavirus makes me so nervous that I can't even do the things I normally do. & 2.24 \\
\hline \multirow{5}{*}{$\begin{array}{l}\text { Social } \\
\text { Subdimension }\end{array}$} & When I see coughing people, the doubt of coronavirus makes me worry extremely. & 3.14 \\
\hline & With the doubt of coronavirus, I run away from people who sneeze. & 3.08 \\
\hline & I'm aware that I spend too much time to clean my hands because of coronavirus. & 2.81 \\
\hline & My social relationships are coming to a full stop for fear of getting coronavirus. & 2.94 \\
\hline & I can't stop myself from the fear of catching coronavirus from others. & 2.81 \\
\hline \multirow{4}{*}{$\begin{array}{l}\text { Economical } \\
\text { Subdimension }\end{array}$} & I'm afraid of food resources running out due to coronavirus. & 2.46 \\
\hline & I'm worried about cleaning items running out due to coronavirus. & 2.20 \\
\hline & I stock up food in fear of coronavirus. & 1.97 \\
\hline & After coronavirus, I'm not at ease if I don't check the supplies in the house. & 2.29 \\
\hline
\end{tabular}

the possibility of a family member getting the coronavirus." getting the highest score may explain this situation. As for the participants with children, even though their C19P-S scores were higher than those without children, it was still not significant. This suggests that this may be due to the health authorities' statement that the risk in children has been low since the beginning of the epidemic or that it may be due to the nature of the participation group we studied. In the study, it was found that only 42 of the participants were living alone, while 968 people were living with more than one person. For this reason, it is thought that it would not be correct to make a clear evaluation due to a large number of differences between groups.

In the study, when we divided the patients into groups as younger than 40 years old and above, no significant difference was found between the groups in terms of C19P-S score, and when we look at the correlation between age and C19P-S score, no significant correlation was found. In terms of the evaluation of generalized anxiety, depression, and sleep disorders related to COVID-19, which was conducted by Huang et al. in China, young individuals showed a significantly higher prevalence of generalized anxiety disorder and depressive symptoms compared to the elderly ${ }^{10}$. In contrast, the study by Yanet Cortes-Alvarez et al. on Mexicans determined that older participants showed more stress than younger people and experienced more psychological distress due to the COVID-19 outbreak ${ }^{11}$. In our country, the government is taking special isolation measures for the elderly population since the beginning of the epidemic may have caused the elderly population to feel more secure, resulting in no significant difference in age in terms of C19P-S score. However, in our study, the ages of the patients were between $18-76$, the average age was 36-54, and the number of elderly patients was relatively small, so we believe that it is not very right to make a crystal clear evaluation.

In this study, the answer "fear of catching coronavirus worries me extremely" given to C19P-S questions ranks second with 3.44 points, and with a point of 3.36 , the answer "The uncertainties about the coronavirus worry me seriously." ranks third. We think that with the decrease in the uncertainties in the course of the coronavirus over time, the participants may experience less fear. 
The limitations of this study can be stated as the fact that it consists of relatively young patients and that the participation is from regions with more urban settlements.

\section{CONCLUSIONS}

We see that in addition to the COVID-19 pandemic affecting the whole society, especially the female population and people with chronic diseases experience much more fear and anxiety.
For this reason, we think that besides the measures to be taken for the whole society, certain measures should be taken to reduce the fear and anxiety in these potentially risky groups.

\section{AUTHORS' CONTRIBUTIONS}

MZ: Conceptualization, Writing - original draft. MK: Conceptualization, Data curation, Formal analysis, Writing review \& editing. NK: Writing - original draft.

\section{REFERENCES}

1. Liu X, Luo WT, Li Y, Li CN, Hong ZS, Chen HL, et al. Psychological status and behavior changes of the public during the Covid-19 epidemic in China. Infect Dis Poverty. 2020;9(1):58. https:// doi.org/10.1186/s40249-020-00678-3

2. Wu Z, McGoogan JM. Characteristics of and important lessons from the Coronavirus Disease 2019 (COVID-19) outbreak in China: summary of a report of 72314 cases from the Chinese Center for disease control and prevention. JAMA. 2020;323(13):1239-42. https://doi.org/10.1001/ jama.2020.2648

3. TR Ministry of Health. COVID-19 Information platform [internet]. 2020 [cited on Aug. 25, 2020]. Available from: https://covid19.saglik.gov.tr/

4. Acar Y. Yeni Koronavirüs (Covid-19) Salgını ve Turizm Faaliyetlerine Etkisi. Güncel Turizm Araştırmaları Dergisi. 2020;4(1):7-21. https://doi.org/10.32572/guntad.703410

5. Arpaci I, Karataş K, Baloğlu M. The development and initial tests for the psychometric properties of the COVID-19 Phobia Scale (C19P-S). Pers Individ Dif. 2020;164:110108. https:// doi.org/10.1016/j.paid.2020.110108

6. Özdin S, Bayrak Özdin Ş. Levels and predictors of anxiety, depression and health anxiety during COVID-19 pandemic in Turkish society: the importance of gender. Int J Soc Psychiatry. 2020;66(5):504-11. https://doi. org/10.1177/0020764020927051
7. Qiu J, Shen B, Zhao M, Wang Z, Xie B, Xu Y. A nationwide survey of psychological distress among Chinese people in the COVID-19 epidemic: implications and policy recommendations. Gen Psychiatr. 2020;33(2):e100213. https://doi.org/10.1136/ gpsych-2020-100213

8. Ozamiz-Etxebarria N, Dosil-Santamaria M, Picaza-Gorrochategui $M$, Idoiaga-Mondragon N. Stress, anxiety, and depression levels in the initial stage of the COVID-19 outbreak in a population sample in the northern Spain. Cad Saude Publica. 2020;36(4):e00054020. https://doi.org/10.1590/0102$311 \times 00054020$

9. Islam MS, Ferdous MZ, Potenza MN. Panic and generalized anxiety during the COVID-19 pandemic among Bangladeshi people: an online pilot survey early in the outbreak. J Affect Disord. 2020;276:30-37. https://doi.org/10.1016/j. jad.2020.06.049

10. Huang Y, Zhao N. Generalized anxiety disorder, depressive symptoms and sleep quality during COVID-19 outbreak in China: a web-based cross-sectional survey. Psychiatry Res. 2020;288:112954. https://doi.org/10.1016/j. psychres.2020.112954

11. Cortés-Álvarez NY, Piñeiro-Lamas R, Vuelvas-Olmos CR. Psychological effects and associated factors of COVID-19 in a Mexican sample. Disaster Med Public Health Prep. 2020;14(3):413-24. https://doi.org/10.1017/dmp.2020.215 